\title{
Research on Innovation and Entrepreneurship Curriculum Reform in Media Universities in the Era of Information Globalization
}

\author{
Mingjun Li \\ Sichuan University of Media and Communications \\ Chengdu, China 611745
}

\begin{abstract}
Information age of globalization, the media industry affects the transformation and industrial development of China's cultural industry depends on the supply of talent, media talents of creative ability of fast and slow media relations directly related to industry transformation class innovation entrepreneurship education in colleges and universities will be able to support the media applied talents of output ratio and form ecological convection, innovative entrepreneurship education is faced with multiple difficulties, innovation promote entrepreneurship curriculum reform and the practice became a realistic problem urgently to be solved.
\end{abstract}

Keywords-information globalization; media innovation; entrepreneurship; curriculum reform; application-oriented talents

\section{INTRODUCTION}

The current China's cultural industry has entered a rapid development and transformation stage, along with the acceleration of globalization of information, the cultural industry in the media industry has entered a new era culture with modern media innovative entrepreneurial spirit and the professional ability of thinking applied talents has become an important topic of the colleges and universities of the current media is also a new era of college talent training new task goal request, is to carry out national first-class construction, the important measures to realize the connotative development strategy at this point. The media class colleges and universities how to construct suitable feasible innovation entrepreneurship, is under the age of information globalization to double a Breakthroughs and reforms in the direction of education

Based on this fact, this paper firstly sorts out and summarizes the innovation and entrepreneurship education and courses of media universities, and then proposes feasible content construction and adjustment for multiple dimensions, such as cultivation objective curriculum setting teaching method, teacher team assessment and evaluation, related to innovation and entrepreneurship courses, combined with the current situation of demand for modern media talents.

\section{CURRENT STATUS OF INNOVATION, ENTREPRENEURSHIP EDUCATION, AND COURSES IN MEDIA UNIVERSITIES}

First, innovation and entrepreneurship education is the slogan, education and teaching consciousness is not clear. For most colleges and universities, innovation and entrepreneurship education is attached to the previous general trend. In order to formally show the content of innovation and entrepreneurship education, for example, related "mass entrepreneurship and innovation" lectures and competitions are carried out. In terms of the practical contents of mass entrepreneurship and innovation education, it fails to improve students' awareness of innovation and entrepreneurship. Many media institutions are the lack of innovative entrepreneurial environment and atmosphere. In the certain innovation entrepreneurship education is a utilitarian purpose, such as too much into advertising and commercial activities, etc., to the improvement of college students' practical ability and professional role in shaping, has lost the practical significance of the innovation of entrepreneurship education, and set the goal of innovation in entrepreneurship does not adapt.

Second, the training objectives of innovation and entrepreneurship courses in media universities are not clear, and the content of the course system is not integrated with practice, resulting in a lack of professional skills in innovation and entrepreneurship. For example, many college students have many entrepreneurial ideas and plans, but they lack good entrepreneurial mentality and confidence. The main reason is the lack of professional courses in innovation and entrepreneurship education, and little understanding of the professional content of entrepreneurship. In particular, students in media colleges and universities are particularly prominent in innovative design of media, but lack the ability in marketing and brand promotion. After a period of entrepreneurship, most students find that there are many problems in the construction of practical contents such as organizational management, strategic planning and marketing strategy. There are products lack of good marketing skills, development prospects and the lack of marketing management ability, finally in a short period of months to be unemployed. Colleges and universities should 
entrepreneurship; (2) to understand the employment status of college students, understand the significance of learning career design and planning; (3) understand and familiar with China's entrepreneurial environment and supporting policies; (4) have college students rights and interests protection and other knowledge; (5) master start-up procedures and operation knowledge of entrepreneurial enterprises; Grasp the basic theoretical knowledge of entrepreneurship and employment. Third, quality objectives: (1) to improve their cognitive ability; (2) cultivate a good professional quality, including professional ethics, professional habits, and professional quality; (3) have a good sense of teamwork; (4) with the spirit of innovation; and improve the logical thinking ability of analyzing and solving problems.

Second, optimize the content of the course and highlight the difficult and easy points. For example, in the first stage of the course content, in order to enable students to get the first knowledge of entrepreneurship, the corresponding teaching content should enable students to master the concept, characteristics and basic elements of entrepreneurship. Know its classification; Master the general process of starting a business. Through case analysis, students can understand the meaning and type of entrepreneurship, define the narrow and broad concept of entrepreneurship, and understand the process of entrepreneurship. Through group discussion to understand the basic quality and ability of entrepreneurship, understand the significance of college student's entrepreneurship. The second stage is to let students know entrepreneurs and entrepreneurial teams (focus). Grasp the characteristics of entrepreneurs; understand the concept of the entrepreneurial team, as well as the principles and procedures of the establishment of the entrepreneurial team; Grasp the ethics and social responsibility of entrepreneurship. The design of specific teaching content is to brainstorm and discuss the strategy of establishing the entrepreneurial team through the analysis of China's current entrepreneurial environment and situation, relevant policies. The third stage is for students to learn about creativity and entrepreneurial opportunities, entrepreneurial resources and entrepreneurial financing, both of which are key contents. The fourth stage is the business plan, business model development, these two are difficult content. The purpose is to let students master how to find entrepreneurial opportunities and evaluate entrepreneurial projects through group discussion. Through case analysis, students can enhance their understanding of career design and planning, and master the basic methods of career design and planning. Finally, through group discussion and team work, students completed the business plan and mastered the writing method of the business plan through practical operation. The fifth stage is the legal issues of entrepreneurship, the growth strategy of new enterprises, the financial statements of enterprises and human resources management. These are the weak points of college students in the media category. For the majority of students, these are both important practical contents and difficult contents.

Third, teaching methods and means. The main methods are task-driven method, visual demonstration method and

visiting teaching method. Task driving method is the use of thinking, can use integrated, systematic, innovative thinking analysis of problems, to solve problems. Second, the knowledge goal: (1) understand the connotation of 
the project team of the roadshow, type, project type, the participatory teaching method, in view of the professional characteristics of different disciplines, to guide students to simulate building virtual company organization form strong business models and professional characteristics, hatched innovative, marketability, forward-looking business projects, cultivate students' teamwork entrepreneurship practice ability and innovation ability. Intuitive presentation method is to enable students to know and understand entrepreneurship from a perceptual perspective through video, audio, text and pictures, and to combine teaching method with discussion method to enable students to have a deeper understanding of Internet + entrepreneurship practice from a rational perspective. The visiting teaching method is to connect students with the startup company, visit the company on the spot, understand the working process of the startup company, understand the cutting-edge knowledge of the startup company, study the operation mode of the startup company, sort out the visiting notes in the group, and write a written report.

Fourthly, the interconnection between theory and practice. The course mainly focuses on the divergence of creative thinking, enhancement of innovation consciousness and training of entrepreneurial ability for students in the direction of media industry with the characteristics of media universities, so as to eventually encourage, guide and help students to start their own businesses successfully. The course adheres to the "double track" mode of combining theory and practice: the first step is to create a "business and innovation training center" to equip students with professional training environment, and then combine with the "business and innovation elite club" to introduce innovative and creative ideas and build the prototype of the project by giving full play to the effect of the club. The club invited the tutor of "business creation and guidance group" to carry out business creation training salon, share professional knowledge and experience, conduct tracking guidance on value projects, and help students incubate projects. The second step is to build a "business guide group" and establish special investment services and channel support. "Business guidance group" is formed by combining actual entrepreneurs and professional teachers. "5+1" mode (5 entrepreneurs and teachers +1 project team) is adopted to guide the project. Meanwhile, special investment services and channel support are constructed to help students incubate the project. The third step is to build linkage with social enterprises, organization of business planning competition, make training with competition to promote education. Combined with the power of social enterprises, organized a professional business planning competition, through the competition to train students and promote the effective transformation of teaching results. The fourth step is to enter the school's business incubation park or relevant supported business incubation industrial park to support the incubation of innovative and entrepreneurial projects, provide students with good early-stage support for entrepreneurship, and improve the survival rate of entrepreneurial projects.

Fifth, the teaching content complementary and the professional linkage aspect. It implements the deep aggregation of interdisciplinary complementary and professional resources (media industry resources: industry, enterprises and institutions), supports the practice of knowledge, strengthens the practice, and promotes the realization of actual combat. "In and out at the same time", with the production, publicity and marketing of the media industry as the main line will be the three disciplines of each major integration. In terms of teaching method innovation, "three teachers and three majors" cross-boundary team strategy, cross-professional teachers with cross-professional students, effectively stimulate students to creative inspiration, innovative thinking activity, and creative inspiration leap. Based on the team, both teaching and learning break the professional boundaries, complementary integration. In the teaching process of multiple aspects, to participate in the daily operation of enterprises, practical projects, belonging to the enterprise team and other ways and cross-professional knowledge combination, so that students have both the role of enterprises, in the actual combat integration of "three specialized" knowledge; Third party enterprise mentors are introduced to guide practice and innovation.

Sixth, the curriculum assessment scientific aspect. Assessment is mainly based on examination, assisted by group work as usual results. It cannot test the professional skills and other abilities required by professionals. The implementation of three-stage (front, middle and late) and "three-party joint examination" (student representatives, teachers' groups and enterprise delegations), accurate grasp of students' creativity and results at each stage, is conducive to the high yield and survival rate of the project. In the early stage, the students' representatives and the guidance teachers' group will conduct self-evaluation and self-examination to grasp the trend of the integration of practice and theory. In the middle period, the teachers' team was mainly responsible for the comprehensive evaluation of executive ability and academic quality, which was a two-way progress. In the later stage, teachers' teams and enterprise delegations were mainly used to comprehensively evaluate the innovation, application and feasibility of the project from different perspectives such as academic and industrial enterprises.

Seventh, the school support and security, mainly in the organization, personnel, funding and policy four security implementation. One is the organization guarantee, set up special education work leading group, innovative undertaking comprehensive plan as a whole, coordinate and promote innovation entrepreneurship education work, there are "double gen" education department and business training center, formulated the "double gen" education implementation plan, supervise the "double gen" education curriculum research and development, organization, foreign exchange and interaction "double gen" education practice evaluation results. The second is personnel security, to create a good working, learning and research environment, especially the necessary material support and guarantee for the tutor team members in the course construction and reform. Third, the fund guarantee, through the school establishment curriculum construction and reform special funds, and into the school's annual budget; At the same time, enterprises and social resources will be used to set up 
[3] Xuejuan Peng, Jiantao Cao, Yuelan Yang, curriculum design of college students' career planning and innovation and entrepreneurship [J], China external education, 2019 (159)

[4] Huihui Wang, research on the problems and countermeasures of the cultivation of application-oriented talents in undergraduate advertising under the "Omnimedia era" [D], central China normal university, 2019 (24)

[5] Wen Qin, strategies of integrating entrepreneurship park and innovation and entrepreneurship education for college students in media universities under the background of "Internet plus" [J], science and technology economics guide, 2019 (104)

\section{EXPECTED RESULTS OF INNOVATION AND ENTREPRENEURSHIP COURSE CONSTRUCTION AND REFORM}

The essence of innovation lies in the practice, the course will need to set up innovation concept, the formation of innovative thinking, innovative method is used to guide innovation activities to focus on strong point, based on media class colleges and universities "cross major, cross-platform, across the curriculum" combination of teaching ideas, to build course system and module, scientific guidance to students entrepreneurial ideas. Expected results will be based on the "Internet" platform, the construction of a new model of online teaching; Create high-quality innovation and entrepreneurship course content; Strengthen the in-depth cooperation with enterprises outside the school; According to the overall teaching effect, constantly improve the curriculum content, carry out the development of training base outside the school; To achieve the goal of students' ability, knowledge and quality.

\section{CONCLUSION}

In the era of information globalization, media colleges and universities should strengthen innovation and entrepreneurship education for college students, especially in the face of problems in curriculum reform, such as weak awareness of education and teaching in innovation and entrepreneurship, and lack of professional skills in innovation and entrepreneurship. Media group's management and teachers of colleges and universities should build a innovation ecological environment, innovation, entrepreneurial business adjustment of curriculum content, teaching methods and means, combined with interest as the guidance for the key breakthrough, to strengthen college students' innovative undertaking education to raise the level of ability in this way can we effectively promote China's cultural industry transformation and development right.

\section{REFERENCES}

[1] Fasheng He, analysis on the integration mechanism of innovation and entrepreneurship education and professional education in media vocational colleges [J], vocational education, 2018 (226)

[2] Dan $\mathrm{Lv}$, Hongtao $\mathrm{Fu}$, Hao $\mathrm{Wu}$, new exploration on innovation and entrepreneurship education for college students in applicationoriented universities from the perspective of "Internet plus" [J], modern vocational education, 2018 (27) 